$16^{\text {th }}$ International Conference on

AEROSPACE SCIENCES \& AVIATION TECHNOLOGY,

ASAT - 16 - May 26 - 28, 2015, E-Mail: asat@ mtc.edu.eg

Military Technical College, Kobry Elkobbah, Cairo, Egypt

Tel : +(202) 24025292 - 24036138, Fax: +(202) 22621908

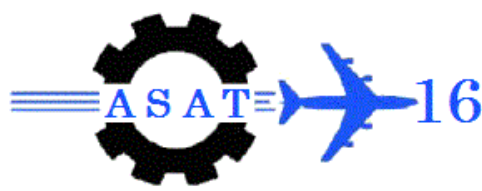

\title{
The Effect of Potassium Perchlorate and Ammonium Perchlorate on the Ballistic Performance of Composite Modified Double Base Propellants
}

By

Ahmed. Fahd. E, Hosam.E. Mustafa, Sherif Elbasuney

\begin{abstract}
Composite modified double-base propellants (CMDB) are characterized with high energy output, wide range of burning rates, as well as enhanced ballistic performance. Recently, much attention has been directed toward the development CMDB. One of the main approaches for the achievement of CMDB includes the integration of an effective oxidizers and fuels, in an attempt to maximize the output heat. This study reports on the effects of potential oxidizers including potassium perchlorate and ammonium perchlorate on the ballistic performance, particularly burning rate, of double base propellant. The ballistic parameters of several CMDB formulations were investigated using a chemical equilibrium computer program named ICT Thermodynamic Code (Institute of Chemical Technology in Germany, virgin 2008). Theoretically, there was an increase in specific impulse with the increase of potassium perchlorate (KP) and ammonium perchlorate (AP) content up to 20 wt.\%. CMDB formulations based on different wt. \% of KP and AP up to 10 wt. $\%$ were manufactured by extrusion process. The practical ballistic performance was evaluated using static test (small scale one inch rocket motor). The two oxidizers exhibited controversy effect. The burning rate was increased by $22 \%$ with the addition of $10 \mathrm{wt}$. \% KP; whereas the characteristic exhaust velocity $\left(\mathrm{C}^{*}\right)$ was increased by $5.3 \%$ with the addition of $10 \mathrm{wt} . \%$ AP. This paper might open the route for the manufacture of CMDB with tailored enhanced performance in terms of specific impulse and burning rate.
\end{abstract}

\section{Keywords}

Burning rate, Composite modified double base propellant (CMDB), Potassium perchlorate, ammonium perchlorate.

\section{Nomenclature}

CMDB Composite modified double-base

$\mathrm{r} \quad$ Burning rate

a Burning rate at unity pressure

$\mathrm{n} \quad$ Burning rate pressure exponent

EDBP Extruded double base propellant

NC Nitrocellulose

NG Nitroglycerine

KP Potassium perchlorate

AP Ammonium perchlorate

* Egyptian Armed Force 


\section{Introduction}

It is well known that composite modified double-base (CMDB) propellants are evolved from double-base (DB) propellants by adding energetic fillers such as HMX or RDX. There is also another trend to integrate potential oxidizers such as AP, and KP as well as active metal fuels such as Al, magnesium, and boron [1-2]. These different additives can diversify the applications and uses of CMDBP in rocket propulsion technologies. This is why CMDB have been recently used as boosters and sustainers and also have been employed for dual thrust rocket motors in tactical missiles. The burning rate and the specific impulse are the main parameters which need to be optimized to meet specific requirements. These critical parameters need to be precisely measured. The burning rate of CMDB can be varied from 7 to $60 \mathrm{~mm} / \mathrm{s}$. This paper investigate the impact of different potential oxidizers mainly AP and KP on the ballistic performance of double base propellant particularly its specific impulse and burning rate.

\subsection{Burning in solid propellants}

In motors running with solid propellant, the burning event is quite complex. Burning models developed so far are still quite simplified. The flame structure, gaseous phases, and other products during the burning can only be demonstrated with mathematical models $[1,3]$.

The burning rate in rocket motors running with solid propellants is expressed as a regression from the combustion surface in terms of time.

The solid propellant burning rate equation known as Vielle's Law is:

$$
\mathrm{r}=\mathrm{a} \mathrm{P}^{\mathrm{n}}
$$

Where, $\mathrm{a}$ is the burning rate constant, $\mathrm{P}$ is the operating pressure, and $\mathrm{n}$ is the pressure exponent. In DB propellant, burning happens without a need for oxygen due to the coexistence of propellant (NG and NC), which are fundamental components of DB fuels.

\subsection{Factors affecting the burning in solid propellants}

In order to find the internal pressure of the rocket motor, it is necessary to determine the geometry of the propellant grain since the internal pressure of the motor depends on its burning area. As the propellant grain burns the burning area changes. For this reason, in order to estimate the motor pressure-time, each burning step of the burning area is needed. The analysis conducted for determining the burning area for each burning step is called "burn back analysis''[4].

\subsubsection{Effects of operating pressure on burning rate}

The operating pressure of the combustion chamber is one of the most important factors on the burning rate. As the operating pressure increases the dark zone decreases and the flame becomes more adjacent to the burning surface (Fig. 1). Therefore the burning rate can proceed faster [5]. 


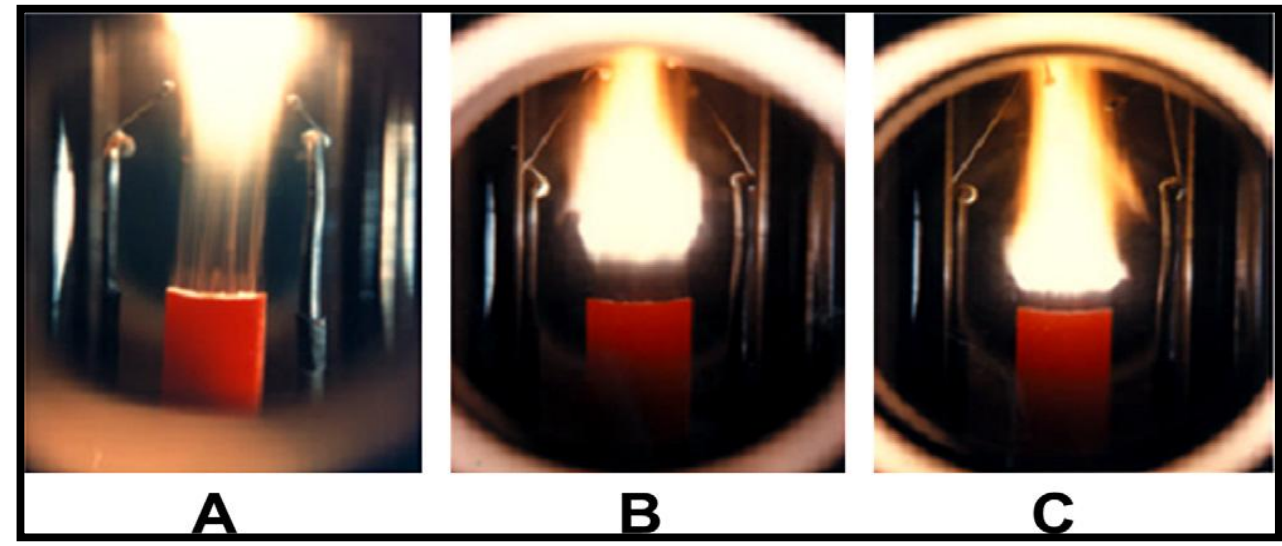

Fig.1: Analysis of flame behavior and rate of double base (NG-NC) solid rocket propellant under different pressures [5]

\subsubsection{Effects of initial fuel temperature on burning rate}

The initial temperature of solid propellants is one of the factors which directly affect the working performance of the rocket. In rocket motors using composite fuel, a change of 25$35 \%$ in combustion chamber pressure and $20-30 \%$ in combustion duration can occur [6-7].

Combustion chamber pressure and combustion duration of initial temperature of the propellant before the burning are given in Fig. 2. As the temperature of propellant increases, the combustion end-pressure increases, the combustion duration shortens, and the specific impulse increases[8].

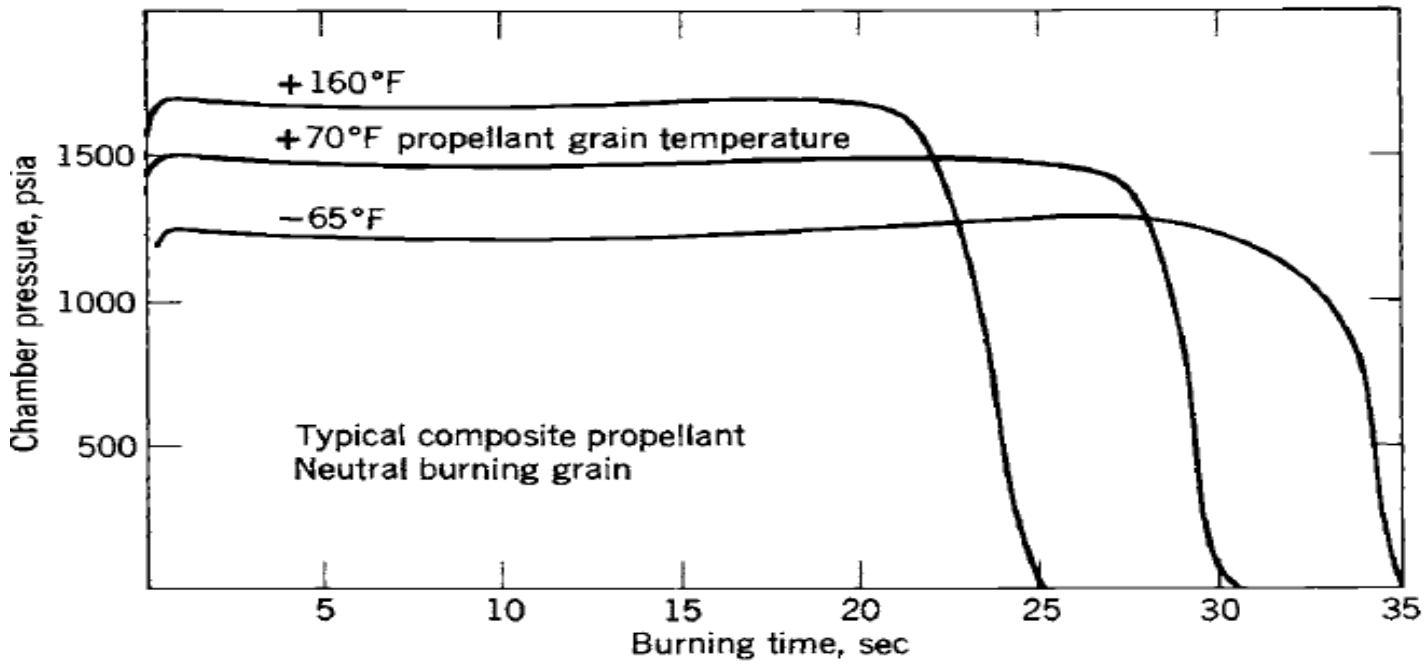

Fig.2: Effect of initial temperature of propellant nucleus on burning rate and chamber pressure.[8]

\subsubsection{Effect of chemical composition on burning rate}

The chemical composition can have a significant impact on the burning rate and specific impulse. For composite CMDB the addition of AP, KP or a reactive nitramine such as RDX allows a higher $I_{S}$ than ordinary DB.

Potential organic oxidizers such as KP and AP have the potential to increase the temperature of the burning surface and improving the heat transfer to the next layer (Stable burning). 
Figure 3 show the effect of oxidizer on the specific impulse and flame temperature respectively.[8]

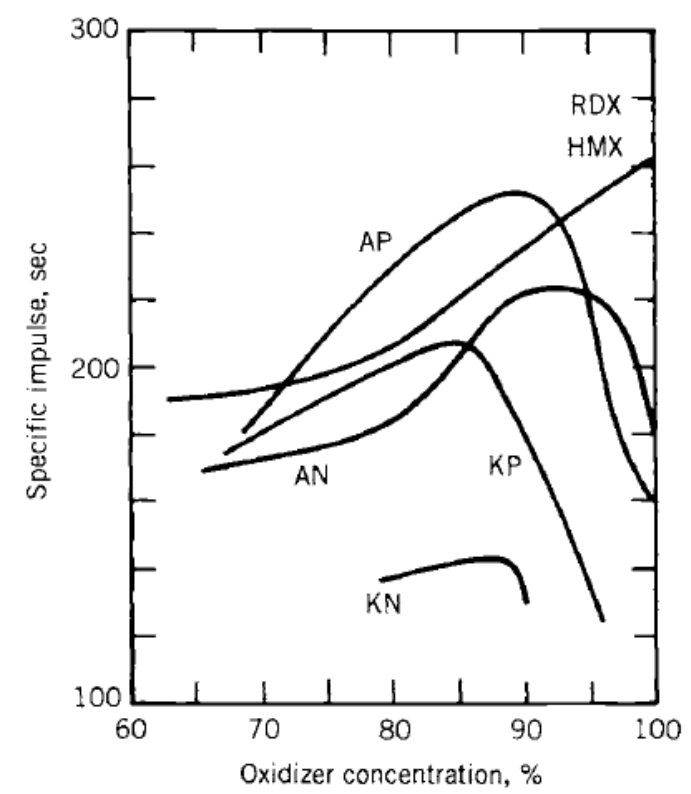

A

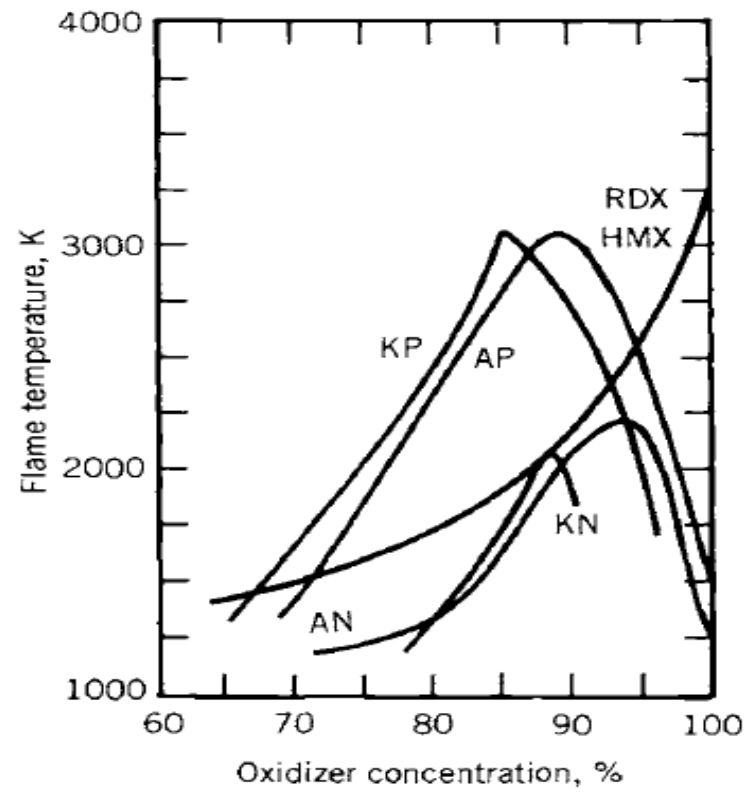

B

Fig.3: Variation of theoretical specific impulse and flame temperature as a function of oxidizer concentration $[8]$

The exothermic decomposition nature of KP is one of the main advantages as it undergoes decomposition at high temperature forming potassium chloride and oxygen gas as demonstrated by equation 2 .

$$
\mathrm{KClO}_{4}+\text { Heat } \rightarrow \mathrm{KCl}+2 \mathrm{O}_{2}
$$

This reaction has a slightly exothermic value of $-0.68 \mathrm{kcal} / \mathrm{mole}$ and produces substantial oxygen. The active oxygen content of KP $(46.2 \%)$ is one of the highest available oxidizer.

$\mathrm{KP}$ is a white, nonhygroscopic crystalline material with a melting point of $610^{\circ} \mathrm{C}$, considerably higher than the $356^{\circ} \mathrm{C}$ melting point of $\mathrm{KClO}_{3}$.[9]

Ammonium perchlorate has found considerable use in modern solid-fuel rocket propellants especially in composite propellant and in the fireworks industry. Ammonium perchlorate undergoes a complex chemical reaction on heating, with decomposition occurring over a wide range, beginning near $200^{\circ} \mathrm{C}$. Decomposition occurs prior to melting, so a liquid state is not produced - the solid starting material goes directly to gaseous decomposition products. The decomposition position reaction is reported by Shimizu to be:[10]

$$
2 \mathrm{NH}_{4} \mathrm{ClO}_{4}+\text { heat } \rightarrow \mathrm{N}_{2}+3 \mathrm{H}_{2} \mathrm{O}+2 \mathrm{HCl}+2.5 \mathrm{O}_{2}
$$

Upon decomposition AP release an active oxygen content of 34\%. The fact that AP generates all gaseous products makes it a valuable material for propellant formulations. The decomposition reaction, above $350^{\circ} \mathrm{C}$, is reported to be considerably more complex:[11]

$10 \mathrm{NH}_{4} \mathrm{ClO}_{4} \rightarrow 2.5 \mathrm{Cl}_{2}+2 \mathrm{~N}_{2} \mathrm{O}+2.5 \mathrm{NOCl}+\mathrm{HClO}_{4}+1.5 \mathrm{HCl}+18.75 \mathrm{H}_{2} \mathrm{O}$

$$
+1.75 \mathrm{~N}_{2}+6.38 \mathrm{O}_{2}
$$


Mixture of ammonium perchlorate and potassium perchlorate should not be used due to the possible formation of unstable (spontaneously explosive) ammonium chlorate in the presence of moisture[12].

The impact of these two oxidizers on DB burning rate as well as specific impulse was thoroughly investigated in an attempt to achieve high burning rate in the mean time maintain the highest possible specific impulse. The two oxidizers exhibited controversy effect. The burning rate was increased by $22 \%$ with the addition of $10 \mathrm{wt}$ \% KP; whereas the characteristic exhaust velocity $\left(\mathrm{C}^{*}\right)$ was increased by $5.3 \%$ with the addition of $10 \mathrm{wt} . \%$ AP. This paper might open the route for the manufacture of CMDB with tailored enhanced performance in terms of specific impulse and burning rate.

\section{Thermochemical calculation.}

Thermochemical methods have been used with considerable success as an effective and fast tool to investigate the characteristics of different types of propellant compositions. The approach of thermochemical calculations becomes of great importance for choosing the propellant formulations that are candidate for proposed practical application and to minimize costly experimental work in order to evaluate efficiently the performance and properties of new propellant compositions.

In this work, the performance parameters of several propellant formulations were calculated using a chemical equilibrium computer program named ICT Thermodynamic Code (Institute of Chemical Technology in Germany, virgin 2008) which is based on the chemical equilibrium and steady-state burning model, The main objective of the presented work is to achieve the parallel need of extrudable and high performance propellant formulations based on double base matrix of nitrocellulose (NC) and nitroglycerine (NG) with addition of KP and AP.Table (1) represents the different chemical compositions of the samples that are investigated by ICT code. 
Table1. Represents the chemical compositions of the samples investigated by ICT code.

\begin{tabular}{|c|c|c|c|c|c|c|c|c|c|}
\hline & \multicolumn{2}{|c|}{ Energetic Base } & \multirow{2}{*}{$\begin{array}{l}\text { Plasticizer } \\
\text { Triacetin }\end{array}$} & \multirow{2}{*}{$\begin{array}{c}\text { Stabilizer } \\
\text { Centralite I }\end{array}$} & \multicolumn{2}{|c|}{ Burning rate modifier } & \multirow{2}{*}{$\begin{array}{c}\text { Opacifier } \\
\begin{array}{c}\text { Carbon } \\
\text { soot }\end{array}\end{array}$} & \multicolumn{2}{|c|}{ Oxidizer } \\
\hline & $\begin{array}{c}\mathrm{NC} \\
(12.1 \%)\end{array}$ & NG & & & $\begin{array}{c}\text { Lead } \\
\text { salicylate }\end{array}$ & $\begin{array}{l}\text { Cupper } \\
\text { resorcylate }\end{array}$ & & $\mathrm{KP}$ & $\mathrm{AP}$ \\
\hline $\mathrm{S} 1$ & 56.20 & 33.55 & 6.00 & 1.80 & 1.60 & 0.70 & 0.15 & 0 & 0 \\
\hline $\mathrm{S} 2$ & 53.44 & 31.85 & 5.70 & 1.710 & 1.50 & 0.66 & 0.14 & 5 & 0 \\
\hline S3 & 50.68 & 30.10 & 5.43 & 1.63 & 1.40 & 0.63 & 0.13 & 10 & 0 \\
\hline $\mathrm{S} 4$ & 47.92 & 28.32 & 5.17 & 1.55 & 1.32 & 0.6 & 0.12 & 15 & 0 \\
\hline S5 & 45.18 & 26.50 & 4.92 & 1.47 & 1.24 & 0.57 & 0.11 & 20 & 0 \\
\hline S6 & 42.44 & 24.68 & 4.68 & 1.40 & 1.16 & 0.54 & 0.10 & 25 & 0 \\
\hline S7 & 53.44 & 31.85 & 5.700 & 1.71 & 1.50 & 0.66 & 0.140 & 0 & 5 \\
\hline S8 & 50.68 & 30.10 & 5.43 & 1.63 & 1.40 & 0.63 & 0.13 & 0 & 10 \\
\hline S9 & 47.92 & 28.32 & 5.17 & 1.55 & 1.32 & 0.60 & 0.12 & 0 & 15 \\
\hline S10 & 45.18 & 26.51 & 4.92 & 1.47 & 1.24 & 0.57 & 0.11 & 0 & 20 \\
\hline S11 & 42.44 & 24.68 & 4.68 & 1.40 & 1.16 & 0.54 & 0.10 & 0 & 25 \\
\hline
\end{tabular}

\section{Experimental work}

\subsection{Materials.}

The chemicals used in this investigation were all of the general laboratory grade; their labeled specifications are mentioned as follows:

(a) NC/NG paste $74 / 26$

Heat of explosion: $1070 \mathrm{cal} / \mathrm{g}$

Moisture content: $25 \%$

Content of nitroglycerine: $25.4-26.6 \%$

Nitrogen content of nitrocellulose: $11.6-11.8 \%$

Source: AZC, Egypt

(c) Centralite I (Stabilizer)

Molecular formula: $\mathrm{C}_{17} \mathrm{H}_{20} \mathrm{~N}_{2} \mathrm{O}$

Mol. Weight: $268.35 \mathrm{~g}$

Density : $0.8 \mathrm{~g} / \mathrm{cm} 3$

Solidification point : $71.5-72.5^{\circ} \mathrm{C}$

Volatile content: Max. $0.1 \%$

Ash content: Max. 0.1\%

Hydrolysable chlorides : Max.0.001\%

Source : Norenco, china

(e) Lead salicylate (Ballistic Modifier)

Molecular formula : $\mathrm{C}_{14} \mathrm{H}_{10} \mathrm{O}_{6} \mathrm{~Pb}$

Appearance : White fine powder

Lead content : $42.2-43.7 \%$

Salicylate content: $55-59 \%$ (b) $\mathrm{NC} / \mathrm{NG}$ paste $50 / 50$

Heat of explosion: $1350 \mathrm{cal} / \mathrm{g}$

Moisture content: $25 \%$

Content of nitroglycerine: $49.4-50.6 \%$

Nitrogen content of nitrocellulose:12.4 -12.6\%

Source: AZC, Egypt

(d) Triacetin (Plasticizer)

Molecular formula: $\mathrm{C}_{9} \mathrm{H}_{4} \mathrm{O}_{6}$

Mol. Weight: $218.707 \mathrm{~g}$

Density : $1.16 \mathrm{~g} / \mathrm{cm} 3$

Melting point : $-78^{\circ} \mathrm{C}$

Boiling point : $259^{\circ} \mathrm{C}$

Heat of combustion : $1006.6 \mathrm{kcal} / \mathrm{mol}$

Oxygen balance $\left(\mathrm{O}_{\mathrm{b}}\right)$ : $-139.31 \%$

Source : Norenco, china

(f) Copper beta -resorcylate (Ballistic Modifier)

Molecular formula : $\mathrm{C}_{14} \mathrm{H}_{10} \mathrm{O}_{8} \mathrm{Cu}$

Synonym: Copper bis (2.4 dihydroxy benzoate)

Colour : Brownish grey

Volatile matter: Max. $4.5 \%$ 
Moisture \& volatiles: Max. 1\%

Insoluble in diethyleneglycol: Max. 2.5\%

Granulation:99.5 \% pass( U.S. std. sieve \# 325)

Source : Normasal, New York, USA

(g) Carbon Black ( C) (Opacifier )

Synonyms : Acetylene black

Moisture: Max. 0.5\%

Ash content: Max. $0.05 \%$

Sulfur content: Max. $0.05 \%$

Specific surface : $60-100 \mathrm{~m}^{2} / \mathrm{g}$

Source :Degussa, France

(i) Ammonium perchlorate (Organic oxidizer)

Molecular weight : $117.49 \mathrm{~g}$

Available oxygen (Weight \%): 34.04

Water solubility $(\mathrm{g} / 100 \mathrm{ml})$ at $20^{\circ} \mathrm{C}: 37.2$

Density : $1950 \mathrm{~kg} / \mathrm{m} 3$

Source: AZC, Egypt
Specific surface : $4-10 \mathrm{~m}^{2} / \mathrm{g}$

Acidity : Max. $30 \mathrm{mg} \mathrm{KOH} / \mathrm{g}$

Particle size : Smaller than 2 micron

Source : Apros Corporation, Korea

(h) Potassium perchlorate (Organic oxidizer)

Molecular weight : $138.55 \mathrm{~g}$

Available oxygen (Weight \%): 46.19

Water solubility $(\mathrm{g} / 100 \mathrm{ml})$ at $20^{\circ} \mathrm{C}: 1.7$

Density : $2520 \mathrm{~kg} / \mathrm{m} 3$

Heat of decomposition: $-0.68 \mathrm{kcal} / \mathrm{mol}$

Source: AZC, Egypt

\subsection{Manufacture of CMDB.}

The employed extrusion production technique emphasizes mixing of different ingredients to ensure homogenization. This technique include many stages such as blending, followed by rolling, grinding, granulation, and finally extrusion to obtain grains of desired shape and dimensions using twin screw extruder.

$\mathrm{NC} / \mathrm{NG}$ pastes containing water of about $30 \%$ were mixed using special kneader for 45 min. These pastes were rolled in two rolling phases to remove water and insure gelatinization by dual effect of pressure and heat. The obtained sheets were subjected to grinding operation, then granulation using screw extruder. The final shaping was achieved using twin screw extruder, with variable feed system and temperature control for screw and die. The exact length of the propellant grains was adjusted using milling saw, lathes mills, and drills. Machining processes control the outside and inside shape of the grain according to required dimensions [13]. Different CMDB formulations with different wt $\%$ of KP and AP were manufactured by extrusion process (Table 2). 
Table 2: The chemical composition of the prepared EDBP formulations

\begin{tabular}{cccccccccc}
\hline & $\begin{array}{c}\text { NC } \\
(12.2 \% \mathrm{~N})\end{array}$ & NG & Centralite I & Triacetin & $\begin{array}{c}\text { Lead } \\
\text { salicylate }\end{array}$ & $\begin{array}{c}\text { Cupper } \\
\text { resorcylate }\end{array}$ & $\begin{array}{c}\text { Carbon } \\
\text { soot }\end{array}$ & KP & AP \\
\hline F0 & 56.20 & 33.55 & 1.80 & 6.00 & 1.60 & 0.70 & 0.15 & 0 & 0 \\
F1 & 53.44 & 31.85 & 5.70 & 1.71 & 1.50 & 0.66 & 0.14 & 5 & 0 \\
F2 & 50.68 & 30.10 & 1.63 & 5.43 & 1.40 & 0.63 & 0.13 & 10 & 0 \\
F3 & 50.68 & 30.10 & 1.63 & 5.43 & 1.40 & 0.63 & 0.13 & 0 & 10 \\
\hline
\end{tabular}

The main constituents are NC and NG, Triacetin, Centralite I, Lead salicylate, Cupper resorcylate, Carbon soot and $\mathrm{KP}$ or $\mathrm{AP}$ as an energetic base, plasticizer, stabilizer, ballistic modifier, Opacifier and organic oxidizer respectively.

\subsection{Characterization and ballistic performance evaluation}

The aim of this work is a comparative study between the effect of KP and AP on the burning rate, characteristic exhaust velocity and pressure time relation on the reference DB propellant formulation.

Three EDBP formulations were prepared with 5\%, $10 \%$ of KP and 10\% AP. The ballistic performance of these CMDB was evaluated using one inch test motors to measure the time of burning, pressure, burning rate, characteristic exhaust velocity and pressure time relation to the reference formulation. The impact of these oxidizers on calorific value $(\mathrm{Qv})$, density and ignition temperature is evaluated.

\subsubsection{Static test (small scale rocket motor).}

For each investigated formulation, a cylindrical specimen of dimension $29 \mathrm{~mm}$ OD, 10 $\mathrm{mm}$ ID and $200 \mathrm{~mm}$ length was manufactured by extrusion. The main ballistic characteristics are obtained from the pressure-time $(\mathrm{P}-\mathrm{t})$ curves and also from the burning rate - pressure relations. In this work the (P-t curves) and the burning rate - pressure relations were obtained experimentally for each formulation. The employed static small scale test motor is shown in figure 4 [14]. 


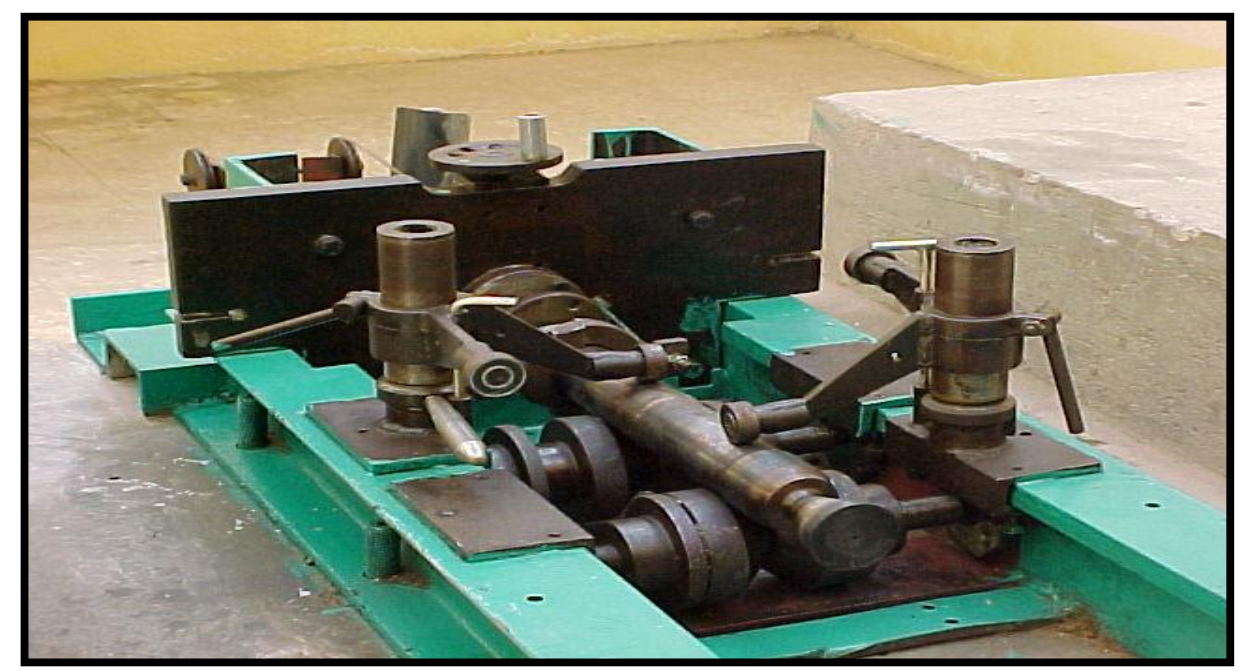

Fig. 4: Propellant test motors assembled before the test

\subsubsection{Determination of Calorific Value}

The calorific value of the investigated formulations was evaluated by the determination of the heat of combustion ( $\mathrm{cal} / \mathrm{g}$ ), which released when one gram of the propellant was completely burned in a closed vessel filled with oxygen. The used bomb calorimeter consisted of two main parts; parr-6200 calorimeter and parr-6510 water handling system.

\subsubsection{Determination of Ignition Temperature}

The ignition temperature is an important characteristic for any prepared propellant. The Reichel \& Partner ignition temperature measurement device (Germany) was employed to determine the ignition temperature for all prepared formulations in this work according to standard procedure[15].

\subsubsection{Density of propellants}

The density of any prepared propellant formulations is an essential property because it judges the accurate content of all ingredients in the propellants.

The Sartorius analytical balance (made in Germany) was used to evaluate the density of all prepared formulations in this work according to the standard technique [15].

\section{Result and discussion}

\subsection{Thermochemical calculations}

The results from thermochemical calculations indicates that ballistic performance particularly the specific impulse, and combustion temperature of the EDBP increases with the increase of the content of KP \& AP until 20 wt \%KP \& $35 \%$ AP. The results of the thermochemical calculation for different investigated samples are tabulated in table 3.

Table.3 Results of the thermochemical calculation for different investigated samples. 


\begin{tabular}{|c|c|c|c|c|c|c|c|}
\hline & $\begin{array}{c}\text { Oxygen } \\
\text { balance } \\
(\mathrm{Ob}) \\
{[\%]}\end{array}$ & $\begin{array}{c}\text { Density } \\
\text { ( } \rho) \\
{[\mathrm{g} / \mathrm{cm} 3]}\end{array}$ & $\begin{array}{c}\text { Characteristic } \\
\text { exhaust } \\
\text { velocity }\left(\mathbf{C}^{*}\right) \\
{[\mathbf{m} / \mathbf{s e c}]}\end{array}$ & $\begin{array}{c}\text { Combustion } \\
\text { temperature } \\
\text { (TC) } \\
{[\mathrm{K}]}\end{array}$ & $\begin{array}{c}\text { specific } \\
\text { impulse( } \\
\text { ISP) } \\
\text { [ sec ] }\end{array}$ & $\begin{array}{c}\text { Number of } \\
\text { moles of } \\
\text { gaseous } \\
\text { products } \\
\text { [mole/kg of } \\
\text { propellant] }\end{array}$ & $\begin{array}{l}\text { Thrust } \\
\text { coefficient } \\
\text { (Cf) }\end{array}$ \\
\hline $\mathrm{S} 1$ & -35.16 & 1.58 & 1396 & 2462.00 & 223.6 & 40.92 & 1.57 \\
\hline $\mathrm{S} 2$ & -31.09 & 1.61 & 1400 & 2571.90 & 224.90 & 39.24 & 1.58 \\
\hline S3 & -27.09 & 1.64 & 1403 & 2683.30 & 225.90 & 37.58 & 1.58 \\
\hline $\begin{array}{l}\text { S4 } \\
\text { S5 }\end{array}$ & $\begin{array}{l}-23.12 \\
-19.17\end{array}$ & $\begin{array}{l}1.67 \\
1.70\end{array}$ & $\begin{array}{l}1403 \\
1401\end{array}$ & $\begin{array}{l}2793.80 \\
2899.40\end{array}$ & $\begin{array}{l}226.50 \\
226.70\end{array}$ & $\begin{array}{l}35.92 \\
34.27\end{array}$ & $\begin{array}{l}1.58 \\
1.59\end{array}$ \\
\hline S6 & -15.27 & 1.74 & 1394 & 2992.60 & 226.20 & 32.63 & 1.59 \\
\hline S7 & -31.69 & 1.59 & 1416 & 2570.80 & 227.30 & 40.15 & 1.58 \\
\hline S8 & -28.30 & 1.61 & 1433 & 2672.90 & 230.50 & 39.40 & 1.58 \\
\hline S9 & -24.94 & 1.62 & 1448 & 2769.10 & 233.30 & 38.66 & 1.58 \\
\hline S10 & -21.60 & 1.64 & 1460 & 2857.80 & 235.70 & 37.92 & 1.58 \\
\hline S11 & -18.31 & 1.66 & 1469 & 2935.80 & 237.70 & 37.20 & 1.59 \\
\hline
\end{tabular}

The specific impulse of the samples increase with increasing the percentage of KP and AP until $20 \%$ of KP and $35 \%$ of AP then begins decrease. This may be illustrated by the percentage of fuel decreases with increasing the percentage of oxidizer till there is not enough fuel to be oxidized and then energy of the propellant falls down and respectively the specific impulse as shown in figure 5.

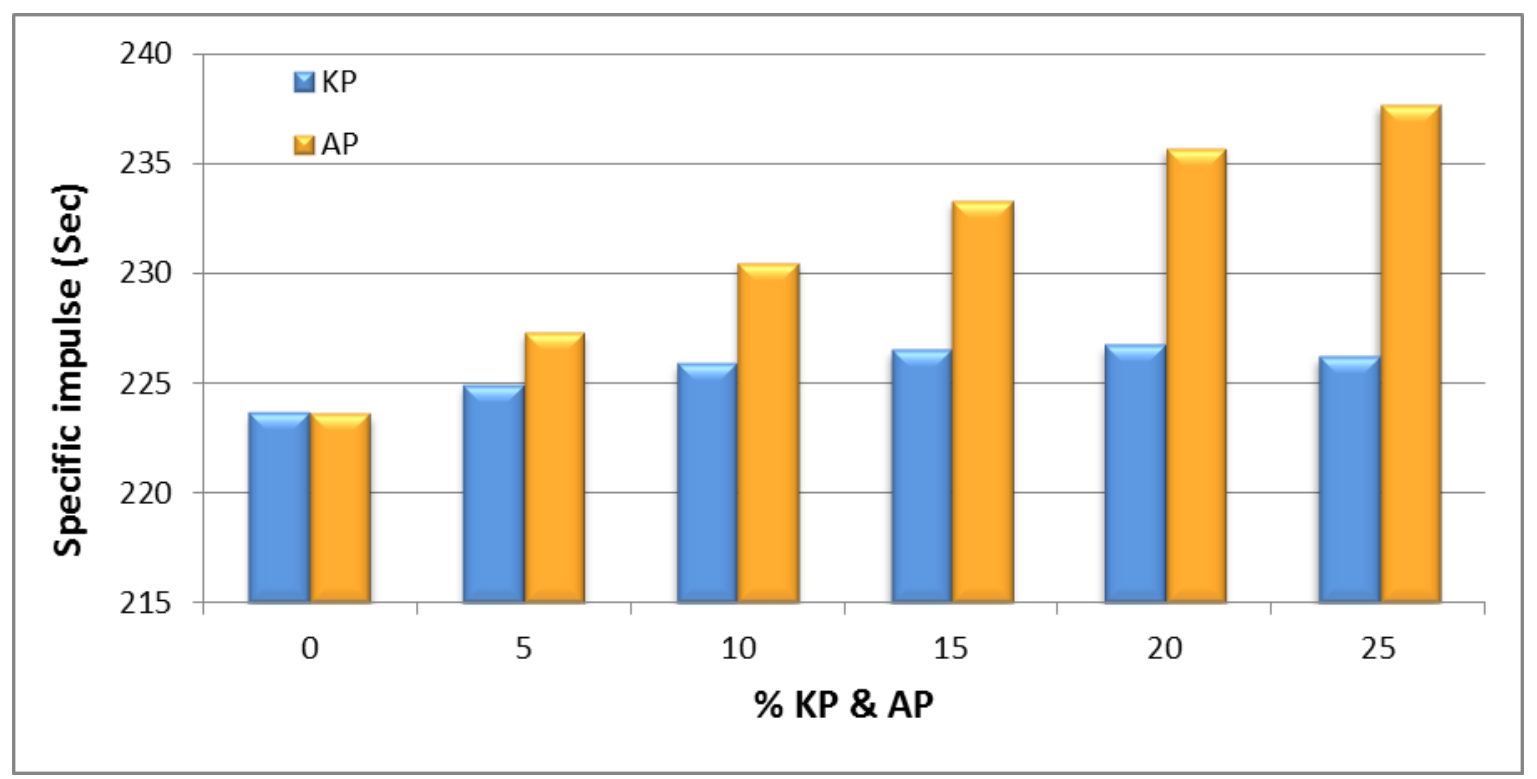

Fig.5: Variation of specific impulse with different percentages of KP\& AP.

It was apparently clear that the impact of AP on the specific impulse is much better than KP. This can be mainly ascribed to the gaseous decomposition nature of AP. The temperature 
of the propellant increases with increasing the wt \% of KP \& AP as demonstrated in figure 6 and 7.

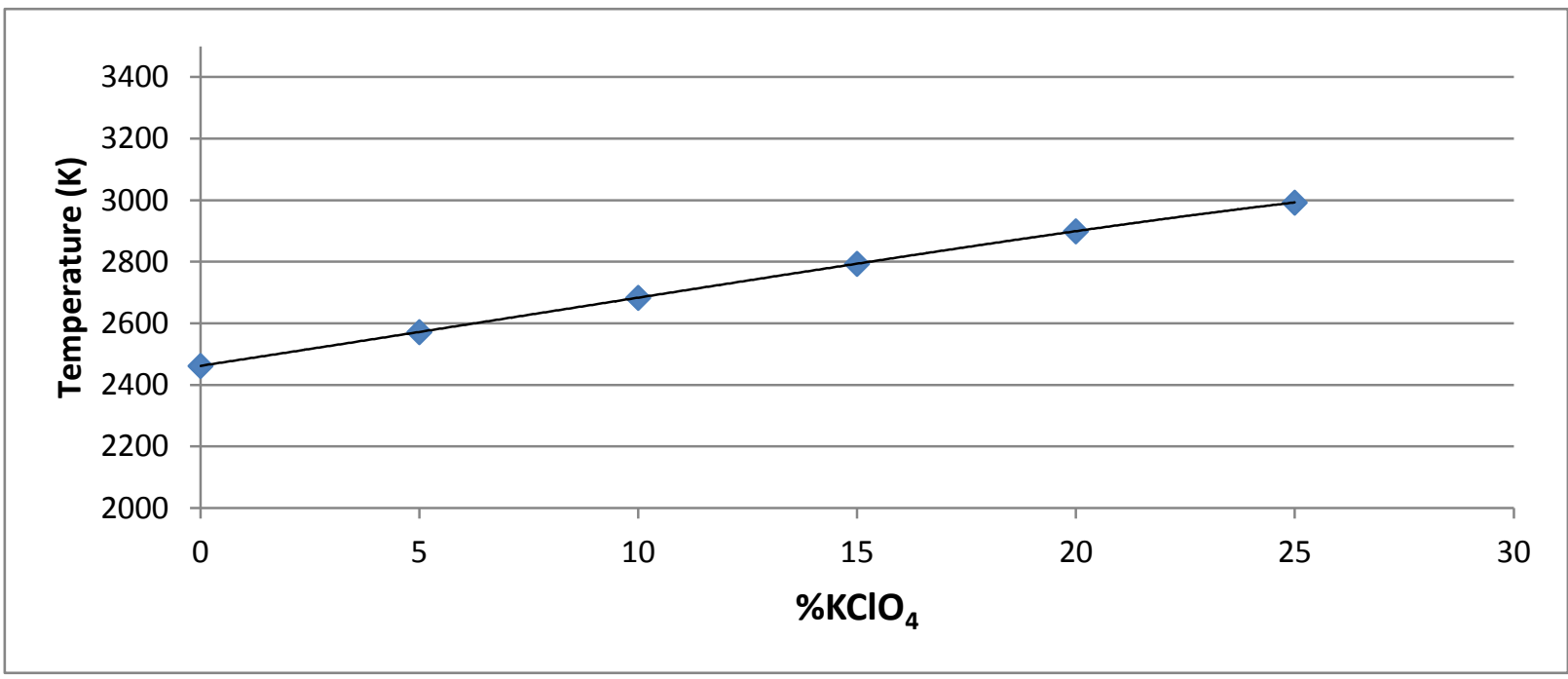

Fig .6: Variation of temperature with different percentages of KP

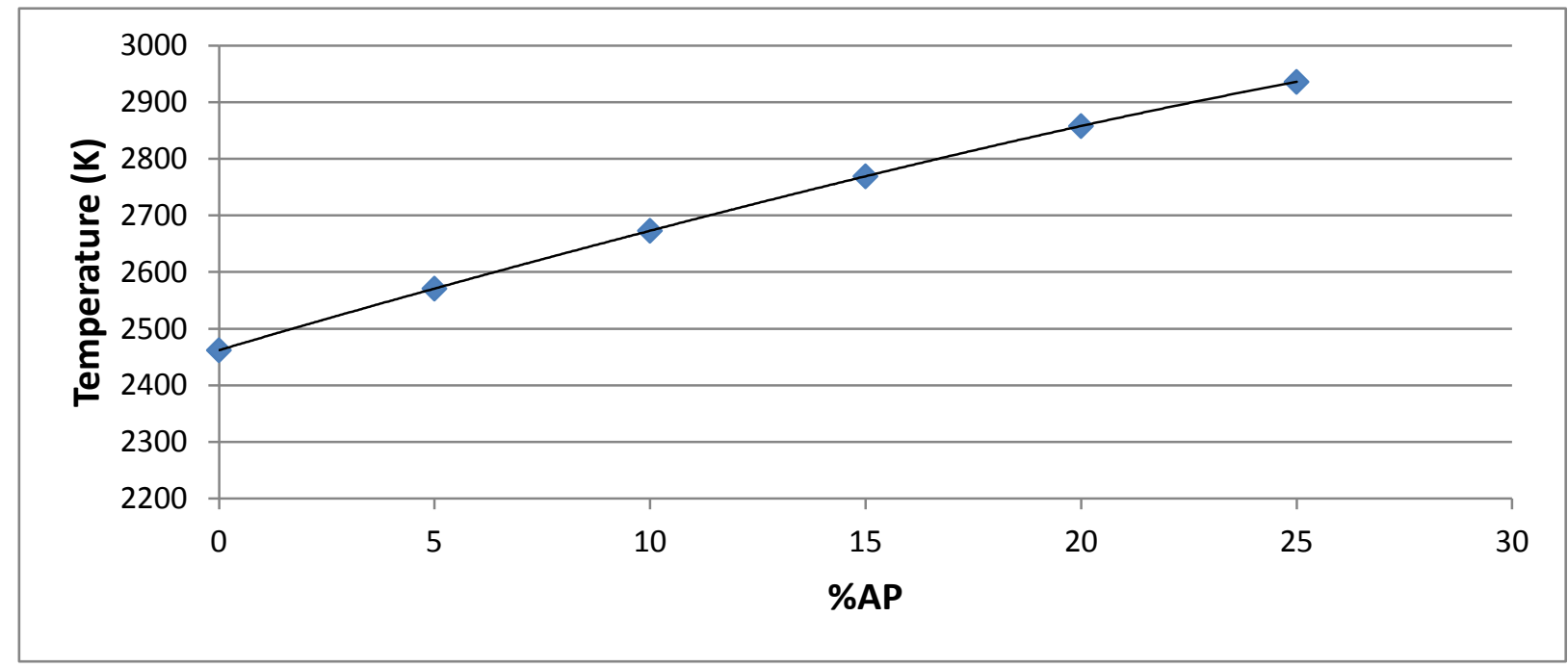

Fig .7: Variation of temperature with different percentages of AP

The increase in combustion temperature can be ascribed to the exothermic oxidation of any hydrocarbon fuel with the available oxidizers and their ability to enhance the oxygen balance. This behavior can add much energy during combustion process [12].

The characteristic exhaust velocity increases with the increase in the wt \% of KP \& AP till approximately $20 \mathrm{wt} \% \mathrm{KP} \& 35 \mathrm{wt} \% \mathrm{AP}$ and then starts to fall down as shown in figure 
8.

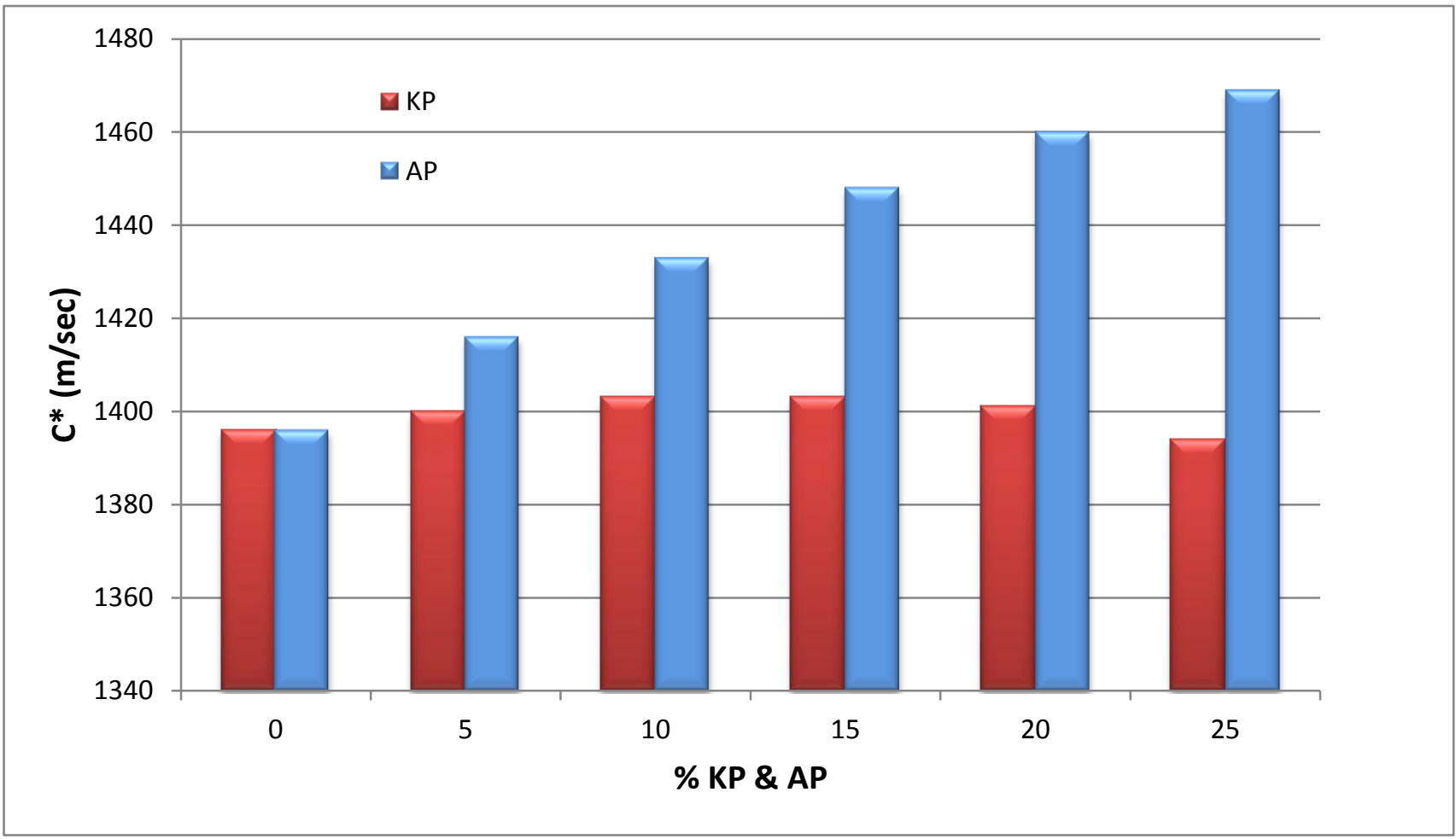

Fig .8: Variation of characteristic exhaust velocity with different percentages of KP\&AP.

The positive impact of AP on $\mathrm{C}^{*}$ characteristic exhaust velocity value can be correlated to its decomposition with the formation of as demonstrated by equation 4 [12].

\subsection{Ballistic performance}

The main characteristic parameters i.e. characteristic exhaust velocity, burning rae, average operating pressure of the investigated formulations (F0, F1, F2 and F3) are demonstrated table 4.

Table 4 Results of the one inch small scale test motor

\begin{tabular}{cccc}
\hline & $\begin{array}{c}\text { Characteristic exhaust velocity }\left(\mathrm{C}^{*}\right) \\
(\mathrm{m} / \mathrm{sec})\end{array}$ & $\begin{array}{c}\text { Burning rate } \\
(\mathrm{mm} / \mathrm{sec})\end{array}$ & $\begin{array}{c}\text { Pressure at 50\% } \\
\left(\mathrm{P}_{50}\right) \quad(\text { Bar })\end{array}$ \\
\hline F0 & 1368 & 25.68 & 278.58 \\
F1 & 1380 & 26.86 & 237.97 \\
F2 & 1400 & 31.33 & 235 \\
F3 & 1440 & 26.55 & 297.96 \\
\hline
\end{tabular}


rate consumed propellant per unit time $(\dot{\mathrm{m}})$. This could be the oxidizer of choice for boosters with high burning rate grains. The main impact of AP at $10 \mathrm{wt} \%$ is the increase in the specific impulse value; this could be the oxidizer of choice in case of sustainers.

The variation of the pressure with time (pressure time curve) for the KP-based formulations (F0, F1, F2) is shown in the figure 9.

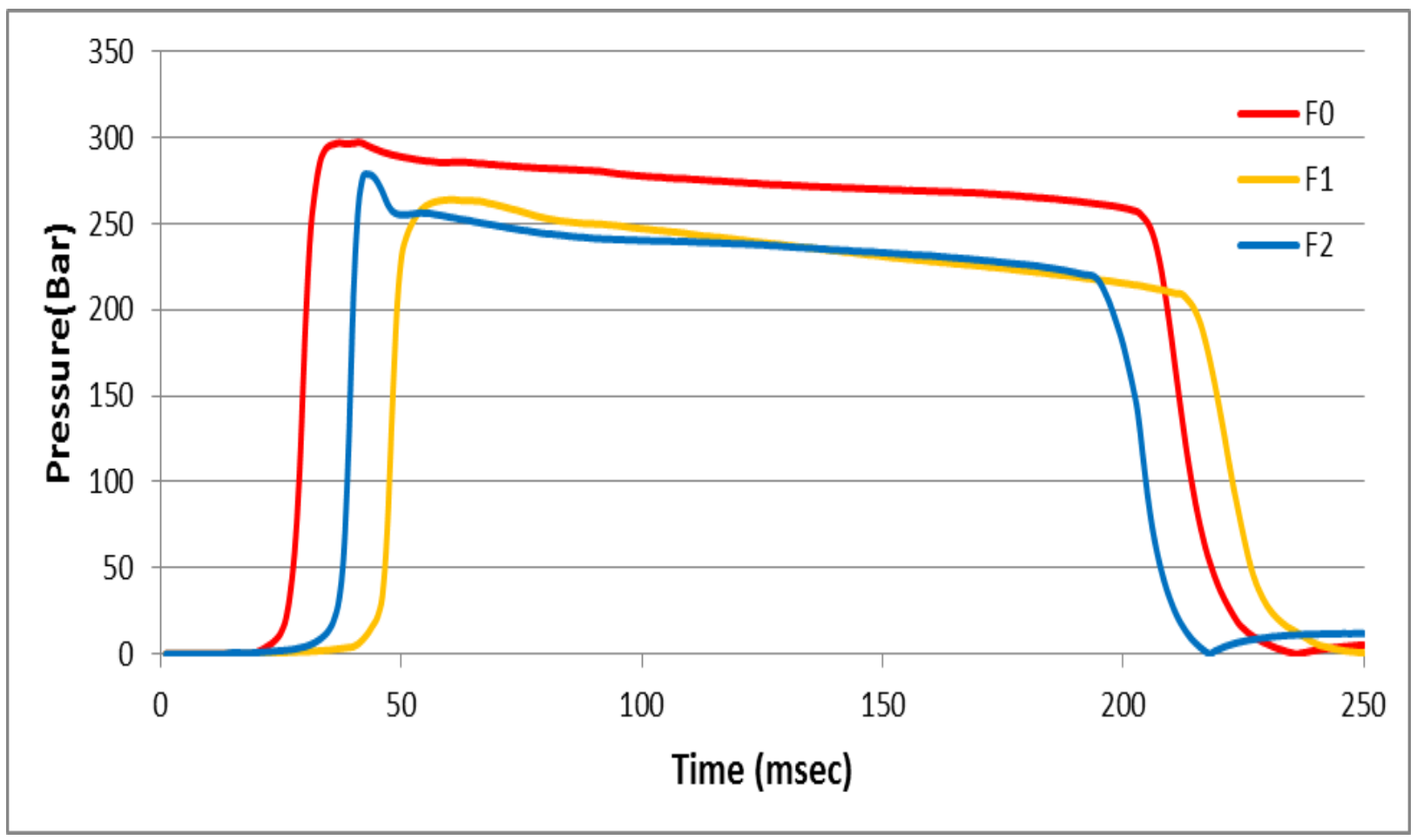

Fig.9: pressure time curve of the three samples (F0, F1and F2)

KP exhibited a dramatic change on the burning rate of the burning rate as it increased by $22 \%$ upon addition of $10 \mathrm{wt} \% \mathrm{KP}$. Also the characteristic exhaust velocity $\left(\mathrm{C}^{*}\right)$ of was increased by $1 \%$ with the addition of $5 \%$ $\mathrm{KP}$ and $2.5 \%$ with addition of $10 \% \mathrm{KP}$ as shown in figure 10. 


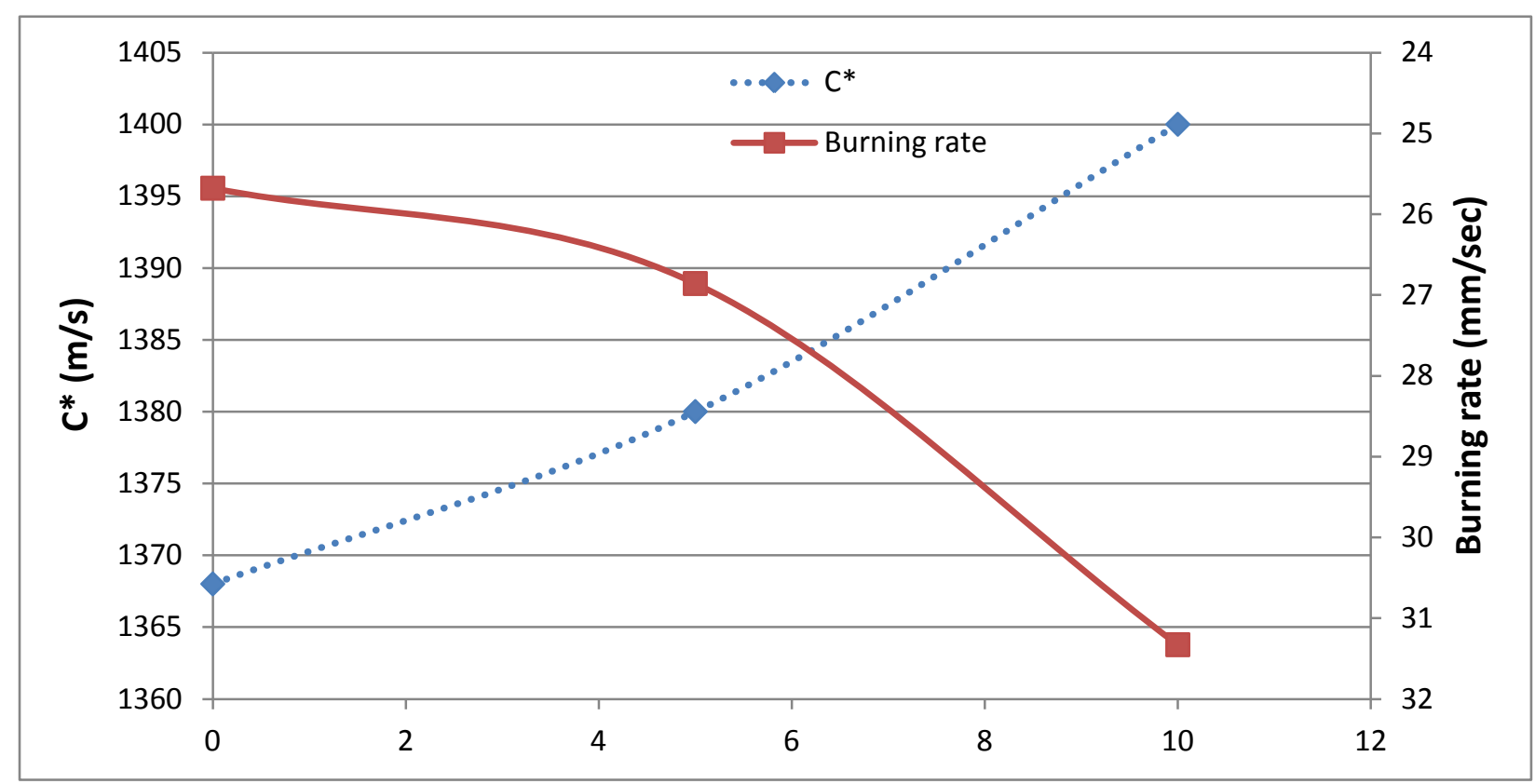

Fig.10: Effect of $\%$ of potassium perchlorate on the burning rate\& $\left(C^{*}\right)$

This effect on burning rate can be ascribed to the high oxidizing power of KP with molecular pyro valence of (-8), as well as its exothermic decomposition. The less impact on the characteristic exhaust velocity can be ascribed to the solid decomposition products as described in equation 2

A comparative study between KP and AP at $10 \mathrm{wt} \%$ on the pressure-time relation resulted from small scale test rocket motor was conducted as described in figure 11.

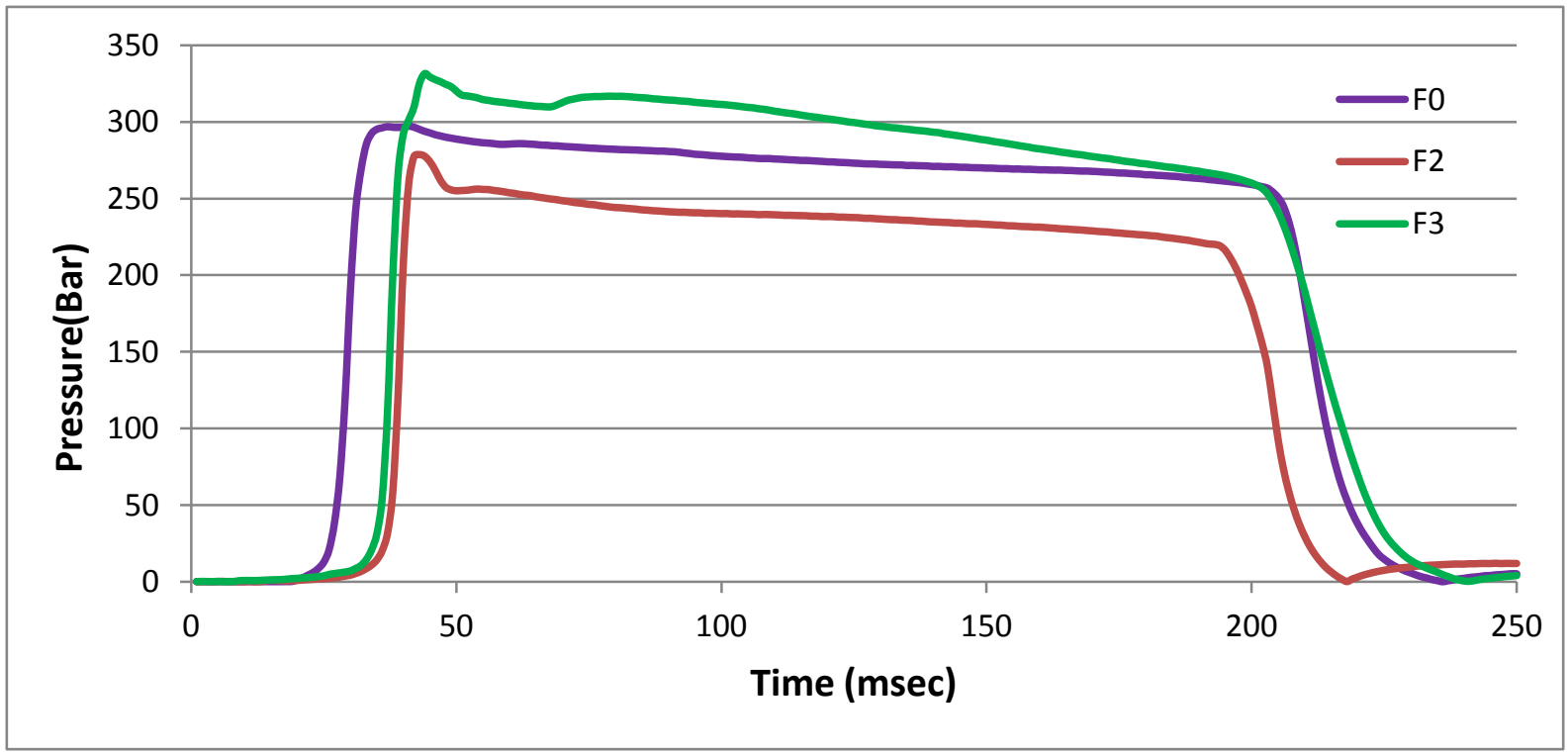

Fig.11: Pressure time curve of the three samples (F0, F2and F3)

The increased pressure inside the rocket motor in case of AP can be ascribed to its decomposition gaseous products. However AP did not greatly impact the burning rate Figure 12 and this could be ascribed to its endothermic decomposition nature, this is why an energetic solid fuel i.e. Al can be used in combination with AP 
to increase the burning temperature and increased burning rate.

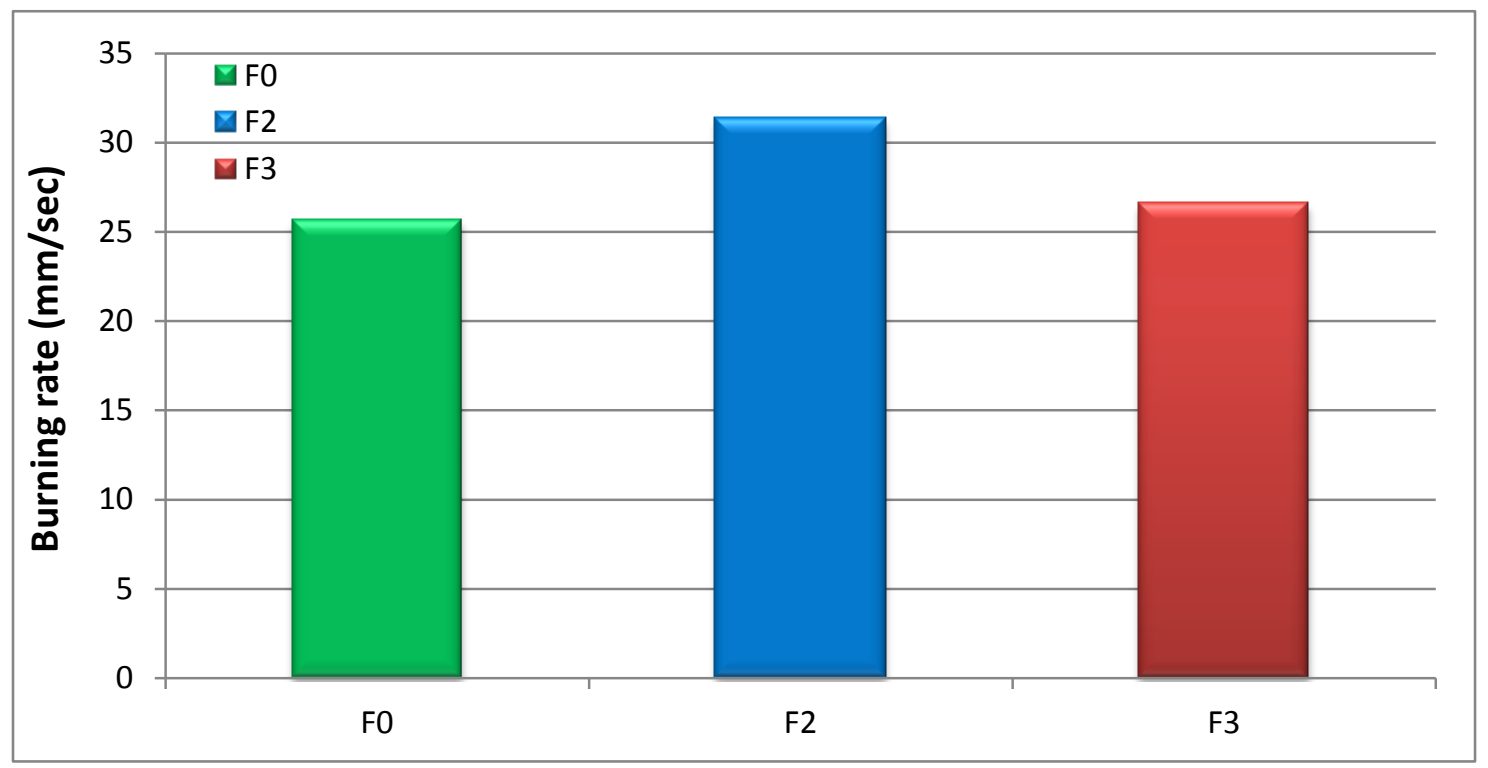

Fig.12: Burning rate of the three samples (F0, F2and F3)

Characteristic exhaust velocity $\left(\mathrm{C}^{*}\right)$ of the reference sample increased from $1368(\mathrm{~m} / \mathrm{sec})$ to $1400(\mathrm{~m} / \mathrm{sec})$ with the addition of $10 \% \mathrm{KP}$ and to1440 (m/sec) with addition of $10 \%$ AP as shown in figure 13 .

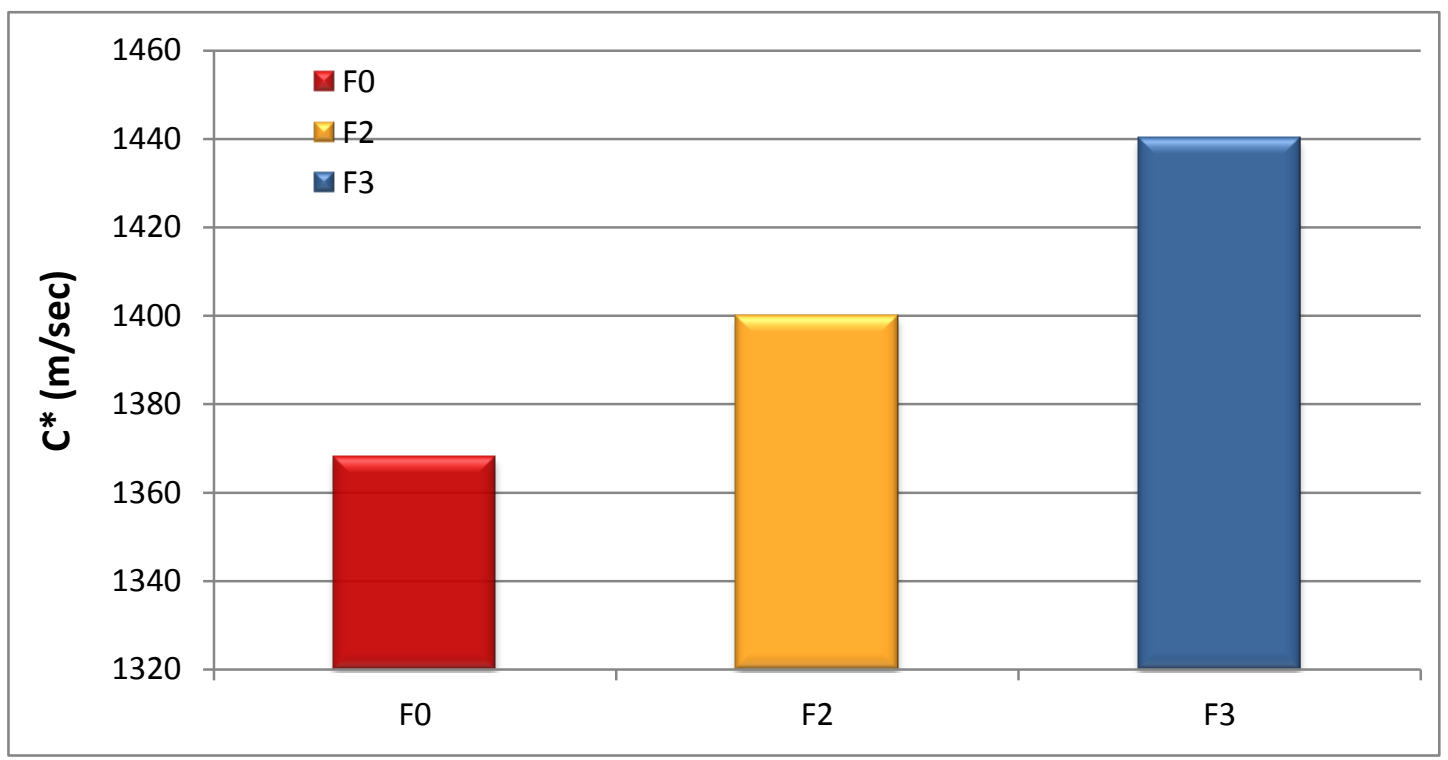

Fig.13: characteristic exhaust velocity of the three samples (F0, F1and F2)

Again, the positive impact of AP on characteristic exhaust velocity can also be described to its decomposition gaseous products. 


\subsection{Thermal and physical properties}

The measured calorific value, ignition temperature and density of the different formulations are tabulated in table 5 .

Table5: Calorific value, Ignition temperature, and density of CMDB formualtions

$\begin{array}{ccc}\text { Calorific value }\left(\mathrm{Q}_{\mathrm{v}}\right) & \text { Ignition temperature } & \text { Density } \\ \mathrm{Cal} / \mathrm{gm} & \left({ }^{\circ} \mathrm{C}\right) & \left(\mathrm{gm} / \mathrm{Cm}^{3}\right)\end{array}$

F0

F1

F2

F3
930

959

1002

947
171

170

171

169

The calorific value of the EDBP formulations increases with percentage of $3 \& 8 \%$ with addition of $5 \& 10$ $\% \mathrm{KP}$ to the reference sample while only $2 \%$ increases with addition of $10 \%$ AP. Also the density of the propellant increase with potassium perchlorate more than ammonium perchlorate from 1.612 to 1.625.

\section{CONCLUSION}

Thermochemical methods have a great importance for choosing the propellant formulations that are candidate for proposed practical application and to minimize costly experimental work in order to evaluate efficiently the performance and properties of new propellant compositions.

Burning rate and characteristic exhaust velocity of the EDBP enhanced with the addition of oxidizer (KP \& AP).

Addition $10 \% \mathrm{KP}$ to the reference sample is more effective in increasing the burning rate than addition $10 \%$ AP which increased the burning rate by $22 \%$ with potassium perchlorate and ammonium perchlorate enhanced the burning rate by $5 \%$ this is due to the exothermic decomposition nature of potassium perchlorate than ammonium perchlorate which increase the calorific value and energy of the propellant.

Calorific value and density of propellant enhanced with the addition of solid inorganic oxidizer.

Ammonium perchlorate is more effective oxidizer in increasing the characteristic exhaust velocity of composite modified double base propellant than potassium perchlorate which enhanced $\left(\mathrm{C}^{*}\right)$ by $5.26 \%$ while potassium perchlorate increased e $\left(\mathrm{C}^{*}\right)$ with $2.34 \%$. 


\section{References}

1. L.Meda, G.L.M., R. Braglia, L. Abis, R. Gallo, F. Severini, L. Galfetti, L.T. DeLuca, A wide characterization of aluminum powders for propellants. Proceedings of the 9-IWCP, Novel Energetic Materials and Applications, grafiche g.s.s,Bergamo, November 2004.

2. Richard A. Yetter, G.A.R., Steven F. Son, Metal particle combustion and nanotechnology, in Proceedings of the Combustion Institute 32. (2009)

3. Sutton, G.P.B., O., Rocket Propulsion Elements. 2011, Wiley. p. 435-554

4. MC, Y., Analysis of grain burnback and internal flow in solid propellant rocket motors in 3-dimensions, in Natural Sciences Institute. 2007, Middle East Technical University: Ankara.

5. Kubota, N., Propellants and explosives: thermochemical aspects of combustion. 2002: Wiley-VCH.

6. Agrawal, J.P., High Energy Materials: Propellants, Explosives and Pyrotechnics. 2010: Wiley.

7. Kosanke KL, K.B., Sturman B, Shimizu T, Wilson MA, von Maltitz I, et al. , in Pyrotechnic chemistry. Pyrotechnic reference series, No: 4. J Pyrotech. USA; 2004. .

8. Sutton, G.P. and O. Biblarz, Rocket Propulsion Elements. 2011, Wiley. p. p 426-430

9. VA., A.M.C.A., Engineering Design Handbook. Military Pyrotechnics Series. Part Three. Properties of Materials Used in Pyrotechnic Compositions. 1963: Defense Technical Information Center.

10. Shimizu, T., Fireworks: The Art, Science, and Technique. 1996: Pyrotechnica Publications.

11. VA., A.M.C.A., Engineering Design Handbook. Military Pyrotechnics Series. Part One. Properties of Materials Used in Pyrotechnic Compositions. 1963: Defense Technical Information Center.

12. Mocella, J.A.C.C.J., Chemistry of Pyrotechnics ,Basic Principles and Theory. 2010, Taylor \& Francis Group, an informa business: USA.

13. Lewis, T.J., The effect of processing variations on the ballistics of fast burning extruded double base propellants. AIAA 14th Joint Propulsion Conference, 1978.

14. R.Fry, L.D., R. Frederick, G. Gadiot, and R. Strecker, "Evaluation of methods for solid propellant burning rate measurement," Defense technical information center ( DTIC) Document, USA, 2002.

15. Nobelkrut, B., Analytical Methods for Powders and Explosives. 1974, Sweden. 